\title{
Bilothorax a Rare Incidence in Thoracic Surgery: Case Report and Literature Review
}

\author{
Ramzi A. Addas, Ahmed M. Alsabban, Abdullah A. Fallatah, \\ Aqeel S. Binaqeel, Salman W. Bafageeh, Abdullah O. Bawazir \\ Department of Thoracic and General Surgery, King Abdulaziz Medical City, Jeddah, KSA \\ Email: ramziaddas79@gmail.com
}

How to cite this paper: Addas, R.A., Alsabban, A.M., Fallatah, A.A., Binaqeel, A.S., Bafageeh, S.W. and Bawazir, A.O. (2021) Bilothorax a Rare Incidence in Thoracic Surgery: Case Report and Literature Review. Open Journal of Thoracic Surgery, 11, 76-82. https://doi.org/10.4236/ojts.2021.113010

Received: August 4, 2021

Accepted: September 19, 2021

Published: September 22, 2021

Copyright $\odot 2021$ by author(s) and Scientific Research Publishing Inc. This work is licensed under the Creative Commons Attribution International License (CC BY 4.0).

http://creativecommons.org/licenses/by/4.0/

\begin{abstract}
Bilothorax or Cholethorax is the accumulation of bilious effusion in the thorax. It is a rare condition in which bile passes into the pleural space from the abdominal cavity, necessitating urgent treatment. This article aims to present a case of bilothorax treated successfully in our institute and review the literature on this topic to better understand this medical problem and the best ways of dealing with it. We presented in this article a case of bilothorax after an attempt of biliary drainage in a known pancreatic cancer patient and the way we managed it. We concluded about the importance of the early recognition of this medical problem and the necessity of aggressive and early management to prevent further morbidities and mortality.
\end{abstract}

\section{Keywords}

Bilothorax, ERCP, Complication, Pleural, Chest Tube Insertion

\section{Introduction}

Bilothorax definition is the presence of bile in the pleural space. Most of the cases in the medical literature are case reports and the majority of these cases are due to iatrogenic injury mainly due to a bile tract injury resulting in a pleurobiliary fistula or from a sub-phrenic abscess formation. In previously reported cases, there has been a different way of managing the condition from conservative management to aggressive surgical intervention [1] [2] [3]. We presented here our experience with a patient that had bilothorax due to iatrogenic reasons and the way we dealt with it. In addition, we did a literature review hoping to give a better understanding of its reasons, diagnosis, and best ways of treatment. 


\section{Case Report}

This is a case of a 50-year-old male known case of pancreatic cancer diagnosed in late 2020. He presented to our hospital with obstructive jaundice. A CT chest and abdomen was performed in February 2021 showed an interval increase in the size of the known mass in the head and uncinate process of the pancreas measuring $5.4 \times 3.9 \times 4.3 \mathrm{~cm}$ in the transverse, anteroposterior, and craniocaudal dimensions while previously it measured $4.6 \times 3.9 \times 3.9 \mathrm{~cm}$ in the same dimensions. There was progression of the intrahepatic and extrahepatic biliary channel dilatation as well as the upstream dilatation of the pancreatic duct. The $\mathrm{CBD}$ is taken off at the pancreatic head and distal CBD stricture is approximately $3-3.5 \mathrm{~cm}$. The mass was persistently encasing the superior mesenteric artery. There was progression of the abdominopelvic ascites. With this distal CBD stricture, it was recommended to undergo an ERCP and if fails can be referred to PTC if clinically appropriate. The patient was referred to interventional radiology suite for percutaneous biliary draining. Cholangiogram was obtained. It showed dilatation in the biliary ducts bilaterally with complete obstruction of the biliary duct at the level of confluence. Over a guidewire, a catheter was advanced and manipulated to pass through the common bile duct. However, the attempt to pass had failed. An 8-F biliary draining catheter was advanced and its pigtail was formed inside the biliary confluence. Contrast medium injection confirmed a good position of the Insertion of 8-F external drainage catheter. There was no immediate complication of the procedure.

The patient's general condition was stable for around a month when he presented to the emergency department complaining of severe shortness of breath, chest pain, and tachycardia. A CT angiography was performed to rule out pulmonary embolism (PE). There was no PE but there was a large right hydropneumothorax compressing the right lung and causing mediastinal shift to the left side [Figure 1] which explains the symptoms the patient was complaining of. In addition, the CT showed that the external biliary drain has an abnormal course through the right pleural cavity and the diaphragm into the liver [Figure 2] which explains the etiology of the accumulation of bile in the thoracic cavity. The imaged upper cuts of the liver show stable biliary dilatation and enlarging/new hepatic lesions worrisome for progression of the hepatic metastasis.

A right-sided chest tube was inserted. Immediate drainage of around $350 \mathrm{~mL}$ of bile was evacuated and the drained fluid had a bile color [Figure 3]. The patient's dyspnoea, tachycardia, and chest pain were relieved after the chest tube insertion. A chest X-ray showed right-sided lung expansion [Figure 4]. Pleural effusion analysis showed a ratio of pleural bilirubin to serum bilirubin $>1$.

As the patient's condition was stabilized and there were no signs of empyema that required surgical intervention, we decided to treat the patient conservatively with close vital signs monitoring, chest tube output surveillance, chest $\mathrm{x}$ rays, and the addition of antibiotics and control of the source. 


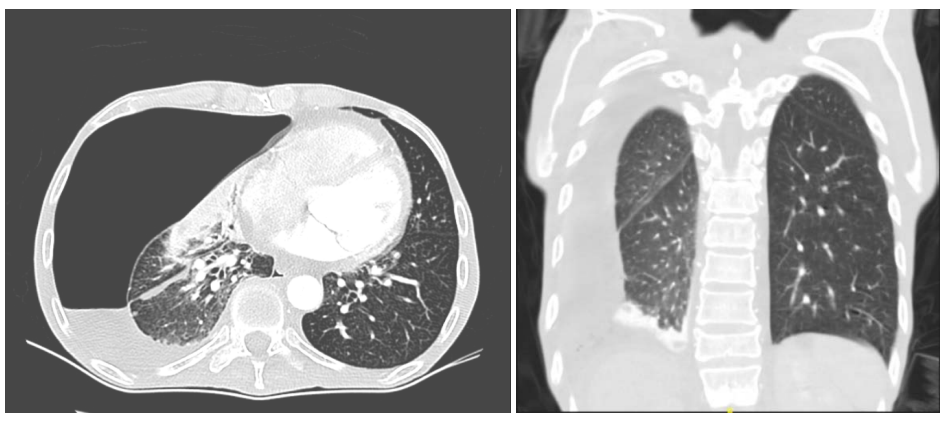

Figure 1. CT Angio was done to rule out pulmonary embolism. There were no embolism but it showed large right hydropneumothorax compressing the right lung and causing mediastinal shift to the left side.
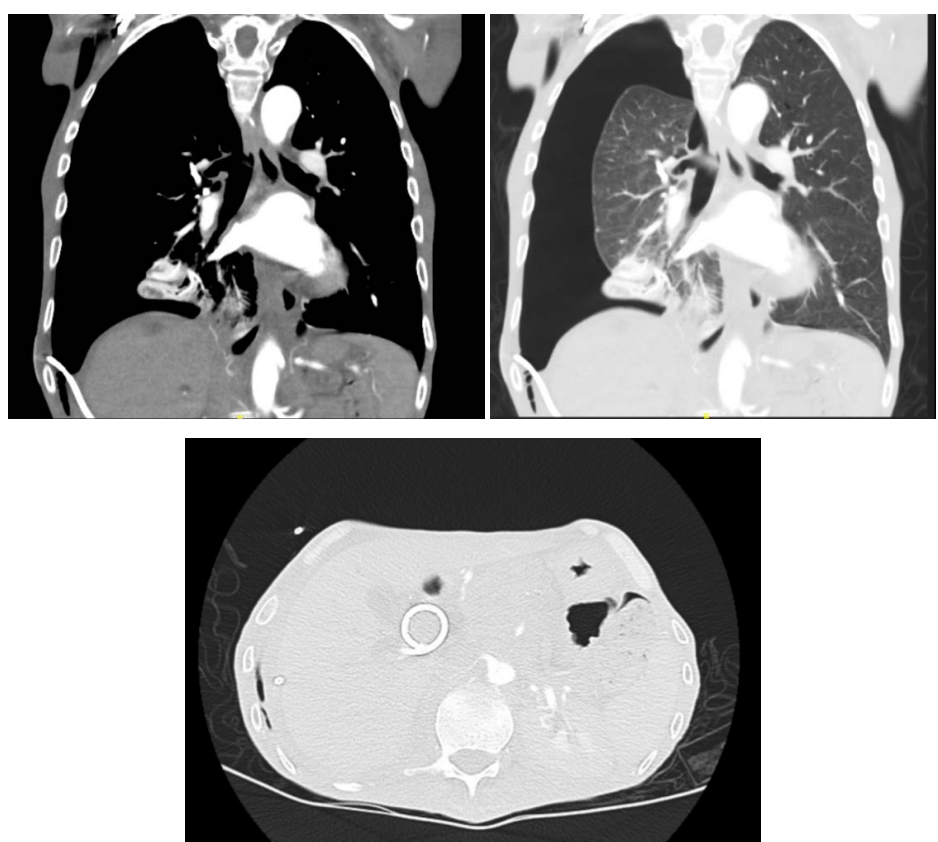

Figure 2. CT showed that the external biliary drain has an abnormal course through the right pleural cavity and the diaphragm into the liver.

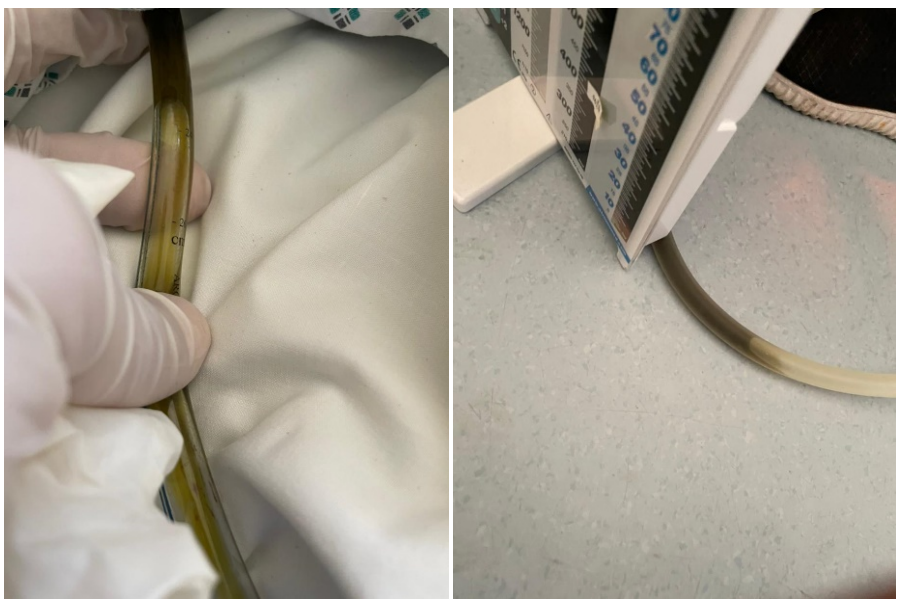

Figure 3. Immediate drainage of around $350 \mathrm{~mL}$ of bile was evacuated and the drained fluid had a bile colour. 


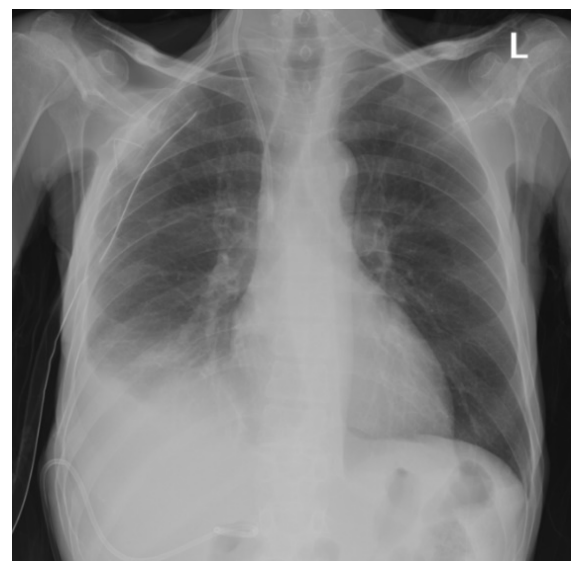

Figure 4. Chest $\mathrm{x}$ ray showed right sided lung expansion.

Regarding the biliary draining catheter, the plan was to remove the one he had and replace it with a new one. That was performed by interventional radiologists. Under ultrasound guidance and approaching from the left side, a branch of the left biliary duct was targeted with $21 \mathrm{G}$ needle and a small amount of contrast confirmed the location inside the biliary system under fluoroscopy. Cholangiogram showed dilatation of the biliary ducts. An 8 Fr biliary draining catheter was placed in the common hepatic duct, the place was confirmed, the catheter was flushed and fixed. Regarding the old biliary drainage, it was removed and its tract was embolized with Gel foam slurry. That was very efficient in stopping the bile leak into the right chest cavity as it was obvious after that procedure that there was no more bile drainage into the right pleural space. The patient's respiratory symptoms were improving and the chest tube was removed three days after the interventionist procedure. We were successful in managing the bilothorax with these steps that we followed.

Unfortunately, the disease progression was fast and the patient passed away due to the advanced metastatic pancreatic cancer that he had.

\section{Discussion}

Bilious pleural effusion is a rare presentation often resulting from an iatrogenic procedural complication involving the gallbladder and biliary tree [1] [2] [3] [4]. It was first reported by Graham when he presented two patients in 1897 (He called them Broncho-biliary fistulas) [5].

The causes of bilothorax have been reported in the literature with variant aetiologies that include a direct extension of a biloma through the diaphragm or through a congenital defect [6] or following traumatic diaphragmatic perforations [7]. One of the major causes is percutaneous biliary drainage [8] as in our case. In other reports, it had been reported to occur after spontaneous gallbladder perforation [9] open cholecystectomy [10] as well as sequel of biliary peritonitis following jejunal, gastric, or bile duct perforations [11] [12]. Presumption of the mechanism of bilious pleural effusion formation in each of 
these cases is small perforations in the diaphragm leading to fenestration of contents from the peritoneal cavity into the pleural space [13]. Suggestions of other theories mentioned that the infected bile erodes through the diaphragm, most commonly through the posterior recess or through a pre-existing defect.

Various theories have been reported regarding the cause of biliary pleural fistula in percutaneous biliary intervention. One of these theories is that the catheter tract may be traversing through the pleural causing an iatrogenic fistula which is probably what occurred in our case as showed in the CT scan. Another theory suggested that due to the obstruction in the biliary tract, the high pressure in the system may cause bile to drain through the pleura. Besides this, the negative pressure during inspiration may suck the bile from the high-pressure biliary tree to the low-pressure pleural cavity. In addition to that, a defect in the diaphragm causes any bile leak to reach the pleural cavity after hepato-biliary operations complicated with biliopleural fistulas which will get matured over time if the fluid (bile) is not drained.

The condition usually presents with cardiorespiratory symptoms in particular dyspnea, cough, pleuritic chest pain, and septicemia.

If not treated properly the respiratory condition of the patient can rapidly get worse not only by lung volume reduction by the fluid but also bile will lead to an inflammatory response due to a directly corrosive effect on the pleural layers which can eventually end with an ARDS.

The association between bilothorax and the development of empyema has been reported in the literature. In the study of Oparah of thoracobiliary fistulization by either gunshot, stab wound, or blunt trauma he reported that out of 16 cases in the literature, twelve patients developed bilious empyema [14]. The most common organisms resulting in complicated and emphysematous bilious effusions are gastrointestinal tract organisms like Escherichia coli, Enterobacter, Klebsiella oxytocin, Enterococcus faecalis, and Staphylococcus aureus [15].

Bilothorax diagnosis is easy in the majority of cases but in others, a high index of suspicion is required. A chest X-ray revealing pleural effusion after liver or biliary procedure should rise the question of the possibility of the bilothorax. When the fluid is drained it will be recognized by its color. Chemical analysis will confirm the diagnosis with a ratio of pleural bilirubin to serum bilirubin $>1$. The mean pleural fluid $\mathrm{pH}$ reported in the literature was 7.16 (range 6.78 to 7.80 ). None of the cases reported in the literature were described as a transudative effusion [15].

Fistulas can be seen few days after the tract has matured between the abdominal and chest cavities in imaging studies like CT scans. Another investigation for diagnosis confirmation is to perform an ERCP which will show a contrast spillage through the biliary tree into the pleural cavity.

Regarding the management of bilothorax although most case reports follow a conservative approach with appropriate drainage through chest tube [16]. It can be avoided by per operative check for bile leaks using propofol or methylene blue but limited data is available regarding this method. Intra-abdominal drains 
may also prevent it, by draining the bile externally instead of towards the pleura.

There is no existing extensive experience regarding the best way of treatment but successful management requires a rapid and accurate diagnosis. Several reports describe conservative management by chest tube insertion and pleural drainage as a successful and appropriate way of solving the problem [17].

Early administration of broad-spectrum antibiotics to prevent future infection is recommended as well [15].

Early and aggressive surgical intervention was suggested in multiple reports [15] as in the surgical management of thoracobiliary fistulas that was proposed by Ferguson and Burford in 1967 [18] after traumas observed during World War II. In that paper, it described the diaphragmatic trauma and the development of bile in the pleural space that required performing thoracotomies, decortication, and repair of the diaphragm.

Minimally invasive procedures advancement and performing the percutaneous drainage of the biliary tree and endoscopic retrograde cholangiopancreatography (ERCP) alleviating biliary obstruction along with pleural drainage is considered to be a very successful approach in managing a lot of bilothorax cases [15].

\section{Conclusion}

Bilothorax is a rare exudative pleural effusion. Its diagnosis needs a high index of suspicion. The main reasons for this respiratory problem are iatrogenic hepatobiliary interventions, abdominal trauma, and hepatic infections. When suspected the pleural effusion should be drained and fluid analysis should be performed which in bilothorax cases we will find a pleural fluid to serum ratio of bilirubin greater than 1 in addition to the biliary colored appearance of the fluid in most of the cases. The first steps of management should include fluid drainage and antibiotic treatment to prevent further respiratory complications such as empyema and respiratory distress. Radiological interventions are essential as well in the management mainly ERCP to treat biliary obstruction in many bilothorax cases. Surgical interventions are required in some cases such as the closure of a persistent unhealing fistula or treating empyema that is not responding to conservative management.

\section{Conflicts of Interest}

The authors declare no conflicts of interest regarding the publication of this paper.

\section{References}

[1] Dasmahapatra, H.K. and Pepper, J.R. (1988) Broncho-Pleuro-Biliary Fistula. A Complication of Intrahepatic Biliary Stent Migration. Chest, 94, 874-875. https://doi.org/10.1378/chest.94.4.874

[2] Herschman, Z., Amin, D. and Lehrfield, A. (1991) Bilious Pleural Effusion as a 
Complication of Attempted Percutaneous Biliary Drainage. Critical Care Medicine, 19, 128-129. https://doi.org/10.1097/00003246-199101000-00035

[3] Pisani, R.J. and Zeller, F.A. (1990) Bilious Pleural Effusion Following Liver Biopsy. Chest, 98, 1535-1537. https://doi.org/10.1378/chest.98.6.1535

[4] Turkington, R.C., Leggett, J.J., Hurwitz, J. and Eatock, M.M. (2007) Cholethorax Following Percutaneous Transhepatic Biliary Drainage. Ulster Medical Journal, 76, 112-113.

[5] Graham, J.E. (1897) Observations on Broncho-Biliary Fistula: With the Reports of Two Cases. British Medical Journal, 1, 1397-1400. https://doi.org/10.1136/bmj.1.1901.1397

[6] Rowe, P.H. (1989) Bilothorax-An Unusual Problem. Journal of the Royal Society of Medicine, 82, 687-688. https://doi.org/10.1177/014107688908201121

[7] Ivatury, R.R. and O'Shea, R.M. (1984) Post Traumatic Thoracobiliary Fistula. The Journal of Trauma, 24, 438-442.

https://doi.org/10.1097/00005373-198405000-00013

[8] Strange, E., Allen, M.L., Freedland, P.N., Cunningham, J. and Sahn, S.A. (1988) Pleural Fistula as a Complication of Percutaneous Biliary Drainage: Experimental Evidence for Pleural Inflammation. The American Review of Respiratory Disease, 137, 959-961. https://doi.org/10.1164/ajrccm/137.4.959

[9] Cunningham, L.W., Grobman, M., Paz, M.L., Hanlore, C.A. and Promisloff, R.A. (1990) Cholecystopleural Fistula with Cholelithiasis Presenting as a Right Pleural Effusion. Chest, 97, 751-752. https://doi.org/10.1378/chest.97.3.751

[10] Prabhu, R., Bavara, C., Purandare, H. and Supe, A. (2005) Pleurobiliary Fistula-A Delayed Complication Following Open Cholecystectomy. Indian Journal of Gastroenterology, 24, 28-29.

[11] Bini, A., Grazia, M., Petrella, F., Stella, F. and Bazzocchi, R. (2004) Spontaneous Biliopneumothorax (Thoracobilia) Following Gastropleural Fistula Due to Stomach Perforation by Nasogastric Tube. The Annals of Thoracic Surgery, 78, 339-341. https://doi.org/10.1016/S0003-4975(03)01282-7

[12] Ramnarin, I.R., Murpur, A.K., McMohan, M.J. and Thorpe, J.A.C. (2001) Pleurobiliary Fistula from Ruptured Choledochal Cyst. European Journal of Cardio-Thoracic Surgery, 19, 216-218. https://doi.org/10.1016/S1010-7940(00)00632-1

[13] Aydogan, A., Erden, E.S., Davran, R., Yetim, I. and Ozkan, O.V. (2013) Cholethorax (Bilious Effusion in the Thorax): An Unusual Complication of Laparoscopic Cholecystectomy. Archives of Iranian Medicine, 16, 489-490.

[14] Oparah, S.S. and Mandal, A.K. (1978) Traumatic Thoracobiliary (Pleurobiliary and Bronchobiliary) Fistulas: Clinical and Review Study. The Journal of Trauma, 18, 539-544. https://doi.org/10.1097/00005373-197807000-00009

[15] Austin, A., Fox, N., Huggins, J.T. and Chopra, A. (2017) The Green Pleural Effusion: A Comprehensive Review of the Bilothorax with Case Series. The Official Journal of the International Society of Pleural Diseases, 4, 21-31.

[16] Petri, C.R., Majid, A. and Anandaiah, A. (2019) A Man with Biliary Sepsis and an Enlarging Pleural Effusion. Annals of the American Thoracic Society, 16, 496-498.

[17] Cooper, Z., Gupta, A. and Odom, S.R. (2012) Conservative Management of a Bilothorax Resulting from Blunt Hepatic Trauma. Annals of Thoracic Surgery, 93, 2043-2044. https://doi.org/10.1016/j.athoracsur.2011.11.024

[18] Ferguson, T.B. and Burford, T.H. (1967) Pleurobiliary and Bronchobiliary Fistulas. Surgical Management. Archives of Surgery (Chicago, Ill: 1960), 95, 380-386. https://doi.org/10.1001/archsurg.1967.01330150056009 